Peer play in inclusive child care settings: Assessing the impact of Stay, Play, \& Talk, a peer-mediated social skills program

\author{
van Rhijn, Tricia \\ University of Guelph \\ Osborne, Caitlyn \\ University of Guelph \\ Ranby, Sarah \\ University of Guelph \\ Maich, Kimberly \\ Memorial University \\ Hall, Carmen \\ Fanshawe College \\ Rzepecki, Lauren \\ University of Guelph \\ Hemmerich, Amanda \\ University of Guelph
}

Note: This is an Accepted Manuscript of an article published by Taylor \& Francis in Child Care in Practice on May 3, 2019, available online:

http://www.tandfonline.com/10.1080/13575279.2019.1588707. 


\begin{abstract}
Peer-mediated interventions are highly effective strategies in supporting the development of social skills for young children; however, research has focused on how peer-mediated interventions are beneficial for children with social communication challenges such as Autism Spectrum Disorder. The goal of this study was to measure the efficacy of Stay, Play, \& Talk for typically developing children in an inclusive child care setting to extend the use of the intervention beyond its previous focus on children with identified or suspected social communication challenges. Using pre- and post-intervention measures, social skills (communication, cooperation, empathy, and responsibility) increased significantly and problem behaviors (hyperactivity/inattention and internalizing behaviors) decreased significantly for children in the intervention group; whereas, their peers in the control group experienced significant increases in communication skills and bullying behaviors. These findings provide preliminary support for the efficacy of this peer-mediated intervention in supporting the development of social skills in typically developing young preschool-aged children.
\end{abstract}

Keywords: peer-mediated intervention; social skills; inclusion; play; preschool; child care

Acknowledgements: This research did not receive any specific grant from funding agencies in the public, commercial, or not-for-profit sectors. 


\section{Peer play in inclusive child care settings: Assessing the impact of Stay, Play, \& Talk, a peer-mediated social skills program}

Social skills play an integral role in children's early development: they are closely related to future success and quality of life. Positive outcomes have been found for children who exhibit more advanced social skills at an early age, including higher academic performance (Malecki \& Elliot, 2002; Wentzel, 2009) and school readiness (Ladd, 1990; McIntyre et al., 2006; Ziv, 2012). In addition, a gap in social skills has been noted between girls and boys at a young age, with boys generally lagging behind in this domain of development (DiPrete \& Jennings, 2011). Due to this developmental gap, in part, many children may require extra support to fully develop these skills, both those with exceptionalities and their typically developing peers (Beckman, 1983; Wylie et al., 1974). Meta-analyses have found that social skills interventions are effective in increasing pro-social behaviors in children (Gresham, 2016). For this reason and others, peermediated interventions have been developed for classrooms to promote social learning through peers (Battaglia \& Radley, 2014). Together, children reach desired social skill outcomes such as initiating play, positively responding to play offers, and engaging in extended periods of play with peers (Hughett et al., 2013).

The focus of this study is Stay, Play, \& Talk, a manualized peer-mediated intervention that can be implemented within inclusive classrooms to help children with special educational needs, as well as their peers, to improve their social skills. For the current study, Stay, Play, \& Talk was incorporated in preschool classrooms to enhance children's social skills. The authors investigated benefits gained by focusing on social skills, including more frequent interactions with peers. This research highlights the need for more effective strategies in developing children's social skills in an early childhood setting. In the following literature review, the importance of social skills development, the role of peer-mediated interventions, and the Stay, Play, \& Talk program is discussed, as well as current gaps in the literature.

\section{Social Skills}

Social skills play a vital role in children's success in their own familial roles and education by allowing them to create long lasting relationships and actively participate in their communities (Arslan et al., 2011; Beauchamp \& Anderson, 2010). These specific skills rely on social development, which involves the abilities to share, communicate, understand social roles, and receive and deliver social responses (Terpstra, 2004). The early years are a critical period in children's development for developing social skills (Arslan et al., 2011). Furthermore, the importance of educational contexts in the early years (e.g., nursery school, child care) has been demonstrated in the development of social skills; in particular, communicative abilities (Marjorano et al., 2009). Teaching these skills at the preschool age also allows for early identification of any developmental concerns or behaviors and, as a result, early interventions can be implemented to foster lagging social skills (Gülay \& Akman, 2009; McIntyre et al., 2006; Webster-Stratton \& Reid, 2004). 
Researchers have identified many benefits related to social development in the early years due to positive developmental outcomes in later childhood, adolescence, and early adulthood (Odom \& Diamond, 1998). Notably, those who acquire good social skills benefit from positive behavioral, psychological, and socio-emotional consequences later on, including higher self-esteem, satisfaction with social interaction, social confidence, and perceived social support (Arslan et al., 2011; Suresh \& Sandhu, 2012). Furthermore, failure to acquire these social skills poses many identified risks in children's futures such as unfavorable school outcomes, poor interactions with others, high rates of disciplinary actions, and other long-term difficulties (Coie \& Jacobs, 1993; Schaefer et al., 2004). A lack of social skills in children can result in rejection by their peers, an inability to form social relationships, and low participation in successful interactions (Gülay \& Akman, 2009). Moreover, when social skills are disrupted, negative outcomes can occur including psychological distress and social isolation (Beauchamp \& Anderson, 2010). These skills lay the foundation for successful future social relationships; therefore, early support for the development of these skills is critical (Gülay \& Akman, 2009).

Social skills also have an influential impact on children's future academic performance (Malecki \& Elliott, 2002; Webster-Stratton \& Reid, 2004). Odom and Diamond (1998), for example, found a negative correlation between increasing levels of social competence in early childhood, and decreasing levels of social adjustment problems in the adolescent years; however, other research has shown that the ability to effectively interact with peers is a strong predictor of early school achievement, success, and interest (McClelland et al., 2000; Rubin et al., 2015). For this reason, young children's capabilities in building peer relationships are important for later school adjustment (Ladd, 1990; Wentzel et al., 2004); teachers and researchers have cited that limited social skills are one of the barriers to school readiness (Lewit \& Baker, 1995; WebsterStratton \& Reid, 2004). Research has also indicated that having a higher number of friends leads to more positive school perceptions and advancing school performance, whereas children who experience peer rejection are at risk for lower school performance, higher school avoidance, and negative school perceptions (Ladd, 1990). The ability for children to form relationships with peers is a vital component of children's social development (Guralnick, 1993; Rubin et al., 2015) and further highlights their need for social skills. Providing extra support may be required for typically developing children and their peers with special educational needs to increase their social skills within inclusive environments (Beckman, 1983; Wylie et al., 1974). In fact, implementing social skill programs in inclusive settings offers typically developing children and children with special needs both the opportunity to develop these skills (Taylor et al., 2002). Therefore, peer-mediated interventions may be implemented to provide this support for children in classroom settings_-including preschool.

\section{Peer-Mediated Interventions}

Early childhood leaders have long advocated for the development of early interventions to address young children's socioemotional and behavioral needs in order to foster the development of social competence; that is, children's active levels of participation in social interactions and play with peers (Stanton-Chapman et al., 2012; Terpstra, 2004). Peer-mediated 
interventions represent an educational approach in which children are provided training and support from educators to act as intervention agents, facilitate behavioral interventions and instructional programs, and collaborate in social interactions with peers who are less socially competent (Chan et al., 2009). Accordingly, peer-mediated programs are most often recognized for promoting peer social relations and interactions for children who have an Autism Spectrum Disorder (ASD) where deficits in social communication are core diagnostic features. Notably though, these programs also promote desired social skill outcomes for typically developing children at all levels of social competencies (Hughett et al., 2013; Odom et al., 1993). At the beginning of the intervention, children are trained to be instructional resources and taught explicit strategies for engaging with peers that emphasize the importance of maintaining eye contact, modeling and reinforcing target social behaviors, initiating play requests, and positively responding to peers' play offers (Hughett et al., 2013). As a result, children are better able to positively construct social interactions, facilitate extended periods of play, and enhance complexity of play activities with their peers. In addition, children become more adept in communication, conflict resolution, mutual cooperation, perspective taking, sharing, and emotional understanding skills (Barbarin \& Wasik, 2009; Chan et al., 2009; Craig-Unkefer \& Kaiser, 2002).

Peer-mediated interventions have emerged as one of the most effective strategies in setting the foundation for the progression of practical social skills to be built upon throughout subsequent educational years (Chan et al., 2009). Children's learning in the classroom presents unparalleled opportunities for children to build social skills with their peers, as play is the primary means by which children develop important social competencies (Barbarin \& Wasik, 2009; Fantuzzo et al., 1998; Harjusola-Webb et al., 2012). An abundance of peers as intervention agents, both in the classroom and across community settings, allows children to learn and practice important social skills in their natural social environment (Battaglia \& Radley, 2014; Chan et al., 2009). The availability of intervention agents significantly reduces demands on educators, while increasing children's access to peer-mediated developmental supports. As more opportunities are created for children to develop practical social skills with their peers, these skills become increasingly generalizable across more individuals and settings (Battaglia \& Radley, 2014; Chan et al., 2009).

Extensive research has been conducted on peer-mediated programs that promote increased social learning (Hughett et al., 2013). An intervention that holds promise for lasting improvements in young children's social behavior is the Buddy Skills Package (Kohler et al., 2007) developed by English and colleagues, including the Stay, Play, \& Talk strategy on which this current project was built (English et al., 1997a; English et al., 1997b). Through training, practice, visual cues, and ongoing teacher support, children learn desired social skill outcomes of engaging in play, initiating share offers, responding positively to play requests, and maintaining mutual attention and communication with their playmates (Hughett et al., 2013; Kohler et al., 2007). Another notable peer-mediated intervention is the LEAP (Learning Experiences and Alternative Program for Preschoolers and Parents) preschool model with educational 
programming involvement for peers, classroom educators, and parents (Hoyson et al., 1984). Positive outcomes demonstrate that typically developing children's social competence is significantly enhanced through extensive, meaningful, developmentally relevant, and highly structured instructional activities with their peers throughout the day (Hoyson et al., 1984; Strain \& Hoyson, 2000). The beneficial outcomes of peer-mediated programs hold promise for improving social skills, such as the specific strategy of Stay, Play, \& Talk program, discussed next.

\section{Stay, Play, \& Talk}

A specific peer-mediated intervention of interest for preschoolers is the Stay, Play, \& Talk program, which was developed through a framework presented in the Buddy Skills Package (Kohler et al., 2007). Several groups in London, Ontario, worked together to adapt this program, including All Kids Belong, Thames Valley Children's Center, and Fanshawe College (Maich, 2012). The resulting manualized program, Stay, Play, \& Talk, is designed to be implemented by early childhood educators and certified teachers within early learning centers and schools for increasing social interactions of preschool children aged three to five years - with their peers. The component of Stay, Play, \& Talk that makes it most exceptional is its focus on peermediated instruction with story-based practices. Research has shown the effectiveness of pairing peer-mediated programs with storybook reading of applicable social situations for increasing social competence in participants (Stanton-Chapman \& Snell, 2011). Originally, this program was designed to support children with special educational needs, and pilot testing of the program supports its efficacy for these children (Maich et al., 2018); however, it has become of increasing interest to examine the benefits of what typically developing children obtain from a peermediated program (Maich, 2012). For this reason, all children are taught to become more aware of each other's social challenges and to view their peers in a positive light (Hall et al., 2011). In turn, children learn more about diversity awareness, social initiations and responses, and specific skills for successfully interacting with peers (Hall et al., 2011; Sperry et al., 2010). The key social skills lessons taught by Stay, Play, \& Talk are (Sperry et al., 2010):

1. Stay with your friends - learn that they must stay with their friend in the same area;

2. Play with your friends - after being taught to stay in the same area as their friend, peers are then encouraged to play with the same materials, (i.e., sharing, turn taking, offering toys); and

3. Talk to your friends - peers are taught how to talk with their friends, engage in pretend play, and talk with each other while engaging in play activities.

As a result of participating in this program, children at all levels of social competencies are supported in achieving desired social skills (Hughett et al., 2013). The Stay, Play, \& Talk program and its step-by-step approach has been shown to be successful in fostering children's social skills, in particular for children with autism (Barber et al., 2016). Therefore, there is a significant need to implement effective strategies for developing children's social skills in early childhood settings. 


\section{Gaps in Literature}

Much focus in previous studies has been placed on how peer-mediated interventions are beneficial for children with ASD (Hughett et al., 2013; Maich et al., 2018). Therefore, it has become of increasing interest to examine the benefits of what typically developing children obtain from a peer-mediated program, such as Stay, Play, \& Talk, as little research has investigated these types of outcomes (Schaefer et al., 2016). Benefits found thus far include more positive attitudes towards peers with intellectual disabilities, and increasing levels of engagement with peers (Schaefer et al., 2016). Still, future research should examine the social and emotional outcomes for typically developing peers in these interventions (Schaefer et al., 2016). More specifically, a study conducted by Locke, Rotheram-Fuller, and Kasari (2012) explored the effect of peer-mediated interventions on typical peer models, noting little increase in social skills for peer models; however, this intervention only used specific peers that were selected and trained to participate in the program with their peers with ASD. Selected peers typically had more developed social skills at baseline and were already connected with their peers with ASD (Locke et al., 2012). Therefore, by including all children in the classroom, as in the current study, it can be hypothesized that there will be more widespread positive outcomes for children's social skills.

By implementing peer-mediated social skill interventions at an earlier age, this developmental gap may be significantly reduced. Therefore, these gaps in research on the effectiveness of peer-mediated interventions for all children, including typically developing peers needs to be addressed.

\section{Current Study}

The current study examines the impact of the Stay, Play, \& Talk program on the development of the social skills and problem behaviors in typically developing children. More specifically, the following hypotheses are evaluated:

1. Children participating in the intervention will have a greater increase in social skills including communication, cooperation, empathy, and responsibility than children who did not.

2. Children participating in the intervention will have a greater decrease in problem behaviors including bullying, hyperactivity/inattention, externalizing, and internalizing than children who did not. 


\section{Participants}

\section{Methods}

Following institutional research ethics board review and approval, a childcare center located on a university campus in southern Ontario, Canada agreed to participate as the intervention site. The sample included six Early Childhood Educators (ECEs) and 39 preschoolaged children enrolled on a full-time basis at the childcare center for whom parental consent was granted. No demographic information was collected for the ECEs; however, they had all completed a minimum of two-years of post-secondary training and five of the six were women.

The preschool-aged children in the study $(N=39)$ included 21 male participants $(53.8 \%)$ and 18 female participants $(46.2 \%)$ for whom both pre- and post-test measures were collected. The age of participants ranged from 24 to 47 months old, averaging 39.17 months (approximately 3.3 years). The majority of participants were assigned to the intervention group $(n=26)$; whereas, the control group consisted of only one playroom in the center $(n=13)$. No further demographic characteristics of the participants were accessible (e.g., cultural background, socioeconomic status).

\section{Procedure}

In order to evaluate the perceived effectiveness of the Stay, Play, \& Talk peer-mediated program in increasing social skills, a five-week quasi-experimental, pre-test/post-test intervention was conducted. First, parents and ECEs each received a letter of invitation introducing them to the project. Next, parents and ECEs each received a package with consent information and the pre-test measures. In addition, the ECEs received extensive group training on the program and were provided with the required resources and materials for their playroom as needed to implement the program. Once the parental consent forms were received, ECEs completed the pre-test measures for each child's social skill development in their playroom. Parents also completed the pre-test measures for their child; however, the decision was made to utilize only the ECEs' measures for the current study as the parents had less opportunity to observe their child's social interactions with their peers. The peer-mediated intervention, Stay, Play, \& Talk, was implemented for the intervention group (that consisted of two preschool playrooms) over the above-noted five-week period following completion of the pre-test measures. Following completion of the program, post-test measures were distributed to parents and ECEs for completion for each child. The one playroom in the center that did not receive the intervention until after time two; therefore, they acted as the control group. The program was implemented in the control group playroom over the five-week period following completion of data collection.

\section{Measures}

The Social Skills Improvement System: Rating Scale (SSIS:RS) developed by Gresham and Elliot (2008) was used to evaluate the effectiveness of the Stay, Play, \& Talk program on increasing children's social skill competencies. This scale was developed to assess and document the frequency of social skills in children, ranging from three to eighteen years of age. Using this 
scale, ECEs in the present study indicated the frequency with which the child displayed each targeted social skill on a four-point Likert type scale with possible responses of: never (1), seldom (2), often (3) and almost always (4). In addition, ECEs also indicated the importance of each social skill to the child's development using a three-point scale of not important, important and critical. For total social skills scores, test-retest reliability estimates have been found in previous analyses to be .82 (Gresham et al., 2010). Subscales include those for social skills and problem behaviors. Four social skills and four problem behavior subscales were used in this study: communication, cooperation, empathy, and responsibility for social skills; bullying, hyperactivity/inattention, externalizing, and internalizing for problem behaviors.

Communication. The communication subscale is made up of seven items. Example items include "takes turn in conversations", "makes eye contact whilst talking", and "initiates conversations". Coefficient alphas for teacher ratings for this subscale in previous work were .85 (Gresham \& Elliot, 2008) and 97 (Gresham et al., 2010).

Cooperation. The cooperation subscale is made up of six items. Example items include "follows your directions" and "participates appropriately in classes". Coefficient alphas for teacher ratings for this subscale in previous work were .90 (Gresham \& Elliot, 2008) and .86 (Gresham et al., 2010).

Empathy. The empathy subscale is made up of six items. Example items consist of "shows concern for others", "feels bad when others are sad", and "nice to others when they are feeling bad". Coefficient alphas for teacher ratings for this subscale in previous work were .88 (Gresham \& Elliot, 2008) and .91 (Gresham et al., 2010).

Responsibility. The responsibility subscale is made up of six items. Example items found on the scale include "well behaved when unsupervised", "takes care when using other people's things", and "takes responsibility for his/her own actions". Coefficient alphas for teacher ratings for this subscale in previous work were .90 (Gresham \& Elliot, 2008) and .90 (Gresham et al., 2010).

Bullying. The bullying subscale is made up of five items. Example items consist of "does things to make others feel scared", "forces others to act against their will", and "is aggressive towards people or objects". Coefficient alphas for teacher ratings for this subscale in previous work were .75 (Gresham \& Elliot, 2008) and .76 (Gresham et al., 2010).

Hyperactivity/inattention. The hyperactivity/inattention subscale is made up of seven items. Example items consist of "has difficulty waiting for turn", "fidgets or moves around too much", and "gets distracted easily". Coefficient alphas for teacher ratings for this subscale in previous work were .90 (Gresham \& Elliot, 2008) and .90 (Gresham et al., 2010).

Externalizing. The externalizing subscale is made up of 12 items. Example items consist of "has temper tantrums", "fights with others", and "disobeys rules or requests". Coefficient alphas for teacher ratings for this subscale in previous work were 93 (Gresham \& Elliot, 2008) and .93 (Gresham et al., 2010).

Internalizing. The internalizing subscale is made up of seven items. Example items consist of "says bad things about self", "acts lonely", and "acts anxious with others". Coefficient 
alphas for teacher ratings for this subscale in previous work were .81 (Gresham \& Elliot, 2008) and .86 (Gresham et al., 2010).

\section{Analysis}

To investigate the two stated hypotheses - that children participating in the intervention would have greater increases in social skills and greater decreases in problem behaviors than the children in the control group - four social skills subscales (communication, cooperation, empathy, and responsibility) and four problem behaviors subscales (bullying, hyperactivity/inattention, externalizing, and internalizing) were each assessed using a Wilcoxon signed-rank test. This test was determined to be appropriate as Shapiro-Wilk tests of the pre- and post-test subscale scores demonstrated that all but two of the scores significantly differed from a normal distribution. The Wilcoxon signed-rank tests were conducted to compare the pre- and post-test scores for each of the two groups (control and intervention).

\section{Results}

Pre- and post-test means and standard deviations on each of the four subscales for each group are included in Table 1. Pre- and post-test internal consistency statistics (i.e., coefficient alphas) were all acceptable and consistent with previous research (Gresham \& Elliott, 2008; Gresham et al., 2010). In addition, comparisons of the control and intervention groups for each of the social skills and problem behaviors pre-test mean subscale scores were made using Mann Whitney $U$ tests to confirm that there were no pre-existing group differences.

\section{Table 1}

Means and standard deviations of pre-and post-communication, cooperation, empathy and responsibility scores for control $(n=13)$ and intervention $(n=26)$ groups.

\begin{tabular}{|c|c|c|c|c|c|c|c|c|c|c|c|}
\hline \multirow[b]{3}{*}{ Subscales } & \multicolumn{6}{|c|}{ Pre-test } & \multicolumn{5}{|c|}{ Post-test } \\
\hline & \multicolumn{2}{|c|}{ Control } & \multicolumn{2}{|c|}{ Intervention } & \multirow[b]{2}{*}{$\alpha$} & \multirow[b]{2}{*}{$U$} & \multicolumn{2}{|c|}{ Control } & \multicolumn{2}{|c|}{ Intervention } & \multirow[b]{2}{*}{$\alpha$} \\
\hline & $M$ & $S D$ & $M$ & $S D$ & & & $M$ & $S D$ & $M$ & $S D$ & \\
\hline \multicolumn{12}{|l|}{ Social skills: } \\
\hline Communication & 2.82 & .67 & 2.75 & .44 & .84 & 155.00 & 3.20 & .70 & 3.06 & .49 & .90 \\
\hline Cooperation & 2.91 & .71 & 2.85 & .55 & .89 & 121.50 & 3.05 & .66 & 3.40 & .45 & .93 \\
\hline Empathy & 2.85 & .60 & 2.87 & .74 & .94 & 166.50 & 2.99 & .77 & 3.29 & .62 & .95 \\
\hline Responsibility & 2.87 & .66 & 2.92 & .47 & .88 & 139.00 & 3.01 & .73 & 3.34 & .49 & .94 \\
\hline \multicolumn{12}{|l|}{ Problem behaviors: } \\
\hline Bullying & 1.35 & .50 & 1.15 & .23 & .78 & 133.00 & 1.60 & .58 & 1.12 & .20 & .85 \\
\hline Hyperactivity & 1.77 & .81 & 1.47 & .35 & .91 & 144.00 & 1.90 & .74 & 1.34 & .26 & .90 \\
\hline Externalizing & 1.54 & .54 & 1.31 & .20 & .88 & 140.00 & 1.69 & .56 & 1.25 & .20 & .91 \\
\hline Internalizing & 1.52 & .43 & 1.30 & .33 & .79 & 126.00 & 1.45 & .47 & 1.14 & .17 & .88 \\
\hline
\end{tabular}

$* p<.05 . * * p<.01 . * * * p<.001$.

Note. Significance tests were conducted on the pre-test subscale means using Mann Whitney U tests; there were no significant differences found between the control and intervention groups for any of the pre-test subscale scores. 
The Wilcoxon signed-rank tests demonstrated support for both hypotheses (see Table 2). For the first hypothesis, ratings of communication, cooperation, empathy, and responsibility were all significantly higher at the post-test for children participating in the intervention, with medium to large effect sizes. Only ratings of communication were significantly higher (with a medium effect size) at the post-test for children in the control group; there were no significant changes in ratings of cooperation, empathy, and responsibility from the pre- to post-test for the children in the control group. For the second hypothesis, ratings of hyperactivity/inattention and internalizing behaviors were significantly lower at the post-test for children participating in the intervention (with medium effect sizes); however, there were no significant change for ratings of bullying or externalizing behaviors. For children in the control group, there were no significant changes in hyperactivity/inattention, externalizing, or internalizing behaviors from the pre- to post-test; however, bullying behaviors were significantly higher at post-test (with a medium effect size).

Table 2

Wilcoxon Signed Ranks Test results comparing pre-and post-test subscale scores for control ( $n$ $=13)$ and intervention $(n=26)$ groups.

\begin{tabular}{|c|c|c|c|c|c|c|}
\hline \multirow[b]{2}{*}{ Subscales } & \multicolumn{3}{|c|}{$\begin{array}{l}\text { Control - pre- \& post-test } \\
\text { comparison }\end{array}$} & \multicolumn{3}{|c|}{$\begin{array}{l}\text { Intervention - pre- \& post-test } \\
\text { comparison }\end{array}$} \\
\hline & $z$ & $p$ & $r$ & $z$ & $p$ & $r$ \\
\hline \multicolumn{7}{|l|}{ Social skills: } \\
\hline Communication & 2.17 & .03 & .60 & 3.79 & $<.001$ & .74 \\
\hline Cooperation & 0.99 & .32 & .27 & 4.23 & $<.001$ & .83 \\
\hline Empathy & 1.03 & .35 & .29 & 4.10 & $<.001$ & .80 \\
\hline Responsibility & 0.94 & .30 & .26 & 4.13 & $<.001$ & .81 \\
\hline \multicolumn{7}{|l|}{ Problem behaviors: } \\
\hline Bullying & 2.09 & .04 & .58 & -1.48 & .14 & -.29 \\
\hline Hyperactivity & 0.45 & .66 & .12 & -2.39 & .02 & -.47 \\
\hline Externalizing & 1.05 & .29 & .29 & -1.31 & .19 & -.26 \\
\hline Internalizing & -0.36 & .72 & -.10 & -2.75 & .01 & -.54 \\
\hline
\end{tabular}

\section{Discussion}

Peer-mediated interventions have been proven to be effective for children with special educational needs, particularly ASD (Katz \& Girolametto, 2013), and are considered an evidence-based intervention for children with ASD (National Autism Center, 2015; Neitzel, 2008; Wong et al, 2013). The goal of this study was to measure the efficacy of Stay, Play, \& Talk for typically developing children to extend the use of the intervention beyond its previous focus on children with identified or suspected social communication challenges. Overall, significant increases were found for all four social skills subscales (communication, cooperation, empathy, and responsibility) and two problem behaviors subscales (hyperactivity/inattention and internalizing) for children in the intervention group. Children in the control group experienced no significant changes in the same period in cooperation, empathy, responsibility, 
hyperactivity/inattention, externalizing, or internalizing behaviors; however, they had significant increases in both communication skills and bullying behaviors. These findings provide preliminary support for the efficacy of this peer-mediated intervention in supporting the development of social skills in typically developing young preschool-aged children which also fit with recent directives on challenging behavior, social-emotional development, and young children (Division for Early Childhood of the Council for Exceptional Children, 2017).

Although Stay, Play, \& Talk was designed and originally implemented to aid in the social skill development of children with special educational needs, these findings suggest that peermediated social skills programs, such as Stay, Play, \& Talk can also support typically developing children who may have underdeveloped or average social skills in reaching their full potential. If social skills programs are implemented in ways that solely focus on impacting children with identified special needs, those who are typically developing could miss opportunities to develop their social skills, as well. Implementing social skills programs across whole classrooms allows for the co-construction of social skills across all children with all abilities (Fenning et al., 2011; Taylor et al., 2002).

\section{Limitations}

There are several limitations that must be recognized within this study. First, the sizes of the control and intervention groups were not equal. An ideal study would have an approximately equal number of participants assigned to each condition. Second, the sample was small, making it less generalizable. Third, the study being conducted at a university campus childcare center may also have had an impact on the results given the combination of higher levels of education and lower turnover rates for ECEs in this center than seen in other community-based centers. Fourth, educators who worked in each of the respective playrooms collected the data. The program was also implemented by each of these educators. Differences in skills and results between children and playrooms may be attributed to individual differences in the ways in which the program was implemented and then reflected on by each educator. Educators' perceptions of children's social skills were used for the pre- and post-test data. Despite being specifically trained for this project, each of these educators may have differing levels of experience observing children, and may also vary in their definitions of the response options. The impacts of these subjective variables may be lessened by implementing further training sessions for educators for the particular rating scales to increase inter-rater reliability and, more generally, in areas such as observation of children and program implementation. Lastly, the program was implemented over a relatively short, five-week period with one of the five lessons for the program being delivered each week. The results could be optimized by allowing educators to have more time to implement the program, and have multiple post-tests to assess the maintenance of the results and whether the skills transferred to the home setting. Further programming time may help to reinforce the positive social skills found in the Stay, Play, \& Talk program. 


\section{Future Research}

Previous work has focused on the effect of peer-mediated programs on enhancing the social skills of children with special educational needs; in particular, children with ASD. In contrast, the current study focused more broadly examining the impact of a peer-mediated program on all children who present varying levels of social skill needs and development. Future research should look at children with special educational needs and typical developing children with an array of social skills and assess whether peer-mediated interventions such as Stay, Play, $\&$ Talk demonstrate significant improvement of social skills in one group in comparison to the other.

The results of the current study provide a foundation for future exploration and research. Researchers should continue to examine the impact of peer-mediated programs assessing a variety of outcomes. Future measures could analyze the quality and frequency of verbal prompts. Assessment of the quality of play and the extent to which it is reciprocated are of particular interest in relation to the development of social skills and social relations. Thus, the use of measures that are objective in nature would be beneficial in studying the duration and reciprocity of play that is deemed a critical role in children's social development. Implementing the program over a longer period would be beneficial to examine the whether the effects are maintained. As well, assessing the outcomes in a variety of settings and procedures, such as small-group intensive teaching sessions, would provide further insight as to whether such skills are generalizable to other social settings and not just the preschool environment. Future research could also closely examine the potential gender differences in social skills and the impact of Stay, Play, and Talk in increasing social competence in disadvantaged childhood groups such as greater emotional expression, understanding of others' emotions, conflict resolution, social communication, and cooperation with peers in boys versus girls (Barbu et al., 2011).

\section{Conclusion}

The successful inclusion of children with special educational needs into inclusive classrooms is a complex process, one of which requires thoughtful creation of social opportunity, and active assistance on behalf of educators and typically developing peers. Peer-mediated inclusion interventions have been deemed advantageous in promoting equitable social opportunities for both children with special educational needs and their typically developing peers within a naturalistic environment. A critical evaluation of relevant literature presented noteworthy gaps in previously targeted age populations, which became the primary basis for this study. Despite potential limitations, the findings of this study contribute to the existing literature relating to social development and inclusion interventions. This study provides support for the efficacy of the Stay, Play, \& Talk program for all children, regardless of ability level. These findings underscore the positive impacts on social skill development for typically developing peers participating in peermediated interventions. Given that typically developing peers act as social models for peers with disabilities, and to contribute to the success of inclusive settings, these findings are particularly important. 


\section{References}

Arslan, E., Durmusoglu-Saltali, N. and Yilmaz, H. (2011). Social skills and emotional and behavioral traits of preschool children. Social Behavior and Personality, 39, 9, pp12811288.

Barbarin, O. A. and Wasik, B. H. (2009). Handbook of child development and early education: Research to practice. New York, NY: The Guilford Press.

Barber, A. B., Saffo, R. W., Gilpin, A. T., Craft, L. D. and Goldstein, H. (2016). Peers as clinicians: Examining the impact of stay play talk on social communication in young preschoolers with autism. Journal of Communication Disorders, 59, pp1-15.

Barbu, S., Cabanes, G. and Le Maner-Idrissi, G. (2011). Boys and girls on the playground: Sex differences in social development are not stable across early childhood. Plos One, 6, 1, ppe16407.

Battaglia, A. A. and Radley, K. C. (2014). Peer-mediated social skills training for children with autism spectrum disorder. Beyond Behavior, 23, 2, pp4-13.

Beauchamp, M. and Anderson, V. (2010). SOCIAL: An integrative framework for the development of social skills. Psychological Bulletin, 136, 1, pp39-64.

Beckman, P. (1983). The relationship between behavioral characteristics of children and social interaction in an integrated setting. Journal of Division for Early Childhood, 7, pp69-77.

Chan, J. M., Lang, R., Rispoli, M., O’Reilly, M., Sigafoos, J. and Cole, H. (2009). Use of peer mediated interventions in the treatment of autism spectrum disorders: A systematic review. Research in Autism Spectrum Disorders, 3, 4, pp876-889.

Coie, J. and Jacobs, M. (1993). Role of social context in prevention of conduct disorder. Development and Psychology, 5, pp263-276.

Craig-Unkefer, L. A. and Kaiser, A. P. (2002). Improving the social communication skills of atrisk preschool children in a play context. Topics in Early Childhood Special Education, 22, 3, pp3-13.

DiPrete, T. A. and Jennings, J. L. (2011). Social and behavioral skills and the gender gap in early educational achievement. Social Science Research, 41, 1, pp1-15.

Division for Early Childhood of the Council for Exceptional Children. (2017). Position statement on challenging behavior and young children. Zero to three, 38, 2, pp33-42.

English, K., Goldstein, H., Shafer, K. and Kaczmarek, L. (1997a). Promoting interactions among preschoolers with and without disabilities: Effects of a buddy skills-training program. Exceptional Children, 63, pp229-243.

English, K., Shafer, K., Goldstein, H. and Kaczmarek, L. (1997b). Teaching buddy skills to preschoolers. Retrieved from ERIC database. (ED415638).

van Rhijn, Osborne, Ranby, Maich, Hall, Rzepecki, \& Hemmerich, 2019 
Fantuzzo, J., Mendez, J. and Tighe, E. (1998). Parental assessment of peer play: Development and validation of the parent version of the Penn Interactive Peer Play Scale. Early Childhood Research Quarterly, 13, 4, pp659-678.

Fenning, R. M., Baker, B. L., \& Juvonen, J. (2011). Emotion discourse, social cognition, and social skills in children with and without developmental delays. Child Development, 82, 2, pp717-731.

Gresham, F. H. and Elliot, S. N. (2008). Social skill improvement system: Rating scales. Bloomington, MN: Pearson Assessments.

Gresham, F., Elliot, S., Cook, C., Vance, M. and Kettler, R. (2010). Cross-informant agreement for ratings for social skills and problem behavior ratings: An investigation of social skills improvement system-rating scales. Psychological Assessment, 22, 1, pp157-166.

Gresham, F.M. (2016). Social skills assessment and intervention for children and youth. Cambridge Journal of Education, 46, 3, pp319-332.

Gülay, H. and Akman, B. (2009). Social skills in the preschool stage [Translated from Turkish]. Ankara: PegemA.

Guralnick, M. (1993). Developmentally appropriate practice in the assessment and intervention of children's peer relations. Topics in Early Childhood Special Education, 13, 3, pp344371.

Hall, C., Kurganker, T., Maich, K., O'Hara, C., Konrad, M. and Balcolm, A. (2011). "Stay, Play, \& Talk” instructional manual. London, ON: Fanshawe College, Thames Valley Children's Center, \& All Kids Belong.

Harjusola-Webb, S., Hubbell, S. P. and Bedesem, P. (2012). Increasing prosocial behaviors of young children with disabilities in inclusive classrooms using a combination of peermediated intervention and social narratives. Beyond Behavior, 21, 2, pp29-36.

Hoyson, M., Jamieson, B. and Strain, P. S. (1984). Individualized group instruction of normally developing and autistic-like children: The LEAP curriculum model. Journal of the Division for Early Childhood, 8, 2, pp157-172.

Hughett, K., Kohler, F. and Raschke, D. (2013). The effects of a buddy skills package on preschool children's social interactions and play. Topics in Early Childhood Special Education, 32, 4, pp246-254.

Katz, E. and Girolametto, L. (2013). Peer-mediated intervention for preschoolers with ASD implemented in early childhood education settings. Topics in Early Childhood Special Education, 33, 3, pp133-143.

Kohler, F. W., Greteman, C., Raschke, D. and Highnam, C. (2007). Using a buddy skills package to increase the social interactions between a preschooler with autism and her peers. Topics in Early Childhood Special Education, 27, 3, pp155-163. 
Ladd, G. W. (1990). Having friends, keeping friends, making friends, and being liked by peers in the classroom: Predictors of children's early school adjustment? Child Development, 61, 4, pp1081-1100.

Lewit, E. and Baker, L. (1995). School readiness. The Future of Children, 5, 2, pp128-139.

Locke, J., Rotheram-Fuller, E. and Kasari, C. (2012). Exploring the social impact of being a typical peer model for included children with autism spectrum disorder. Journal of Autism and Developmental Disorders, 42, 9, pp1895-1905.

Maich, K. (2012). Stay, Play, \& Talk: A peer-mediated social skills program for children with

ASD and other social challenges and their peers. ETFO Voice. Retrieved from: http://etfovoice.ca/node/728

Maich, K., Hall, C., van Rhijn, T., \& Squires, K. (2018). Investigating Stay, Play, \& Talk: A peer-mediated social skills intervention for young children with Autism Spectrum Disorder and social challenges. Exceptionality Education International, 28, 2, pp82-104. Retrieved from https://ir.lib.uwo.ca/eei/vol28/iss2/5

Malecki, C. K. and Elliott, S. N. (2002). Children's social behaviors as predictors of academic achievement: A longitudinal analysis. School Psychology Quarterly, 17, 1, pp1-23.

Marjorano, M., Cigala, A., \& Corsano, P. (2009). Adults' and children's language in different situational contexts in Italian nursery and infant schools. Child Care in Practice, 15, 4, pp279-297.

McClelland, M. M., Morrison, F. J. and Holmes, D. L. (2000). Children at risk for early academic problems: The role of learning-related social skills. Early Childhood Research Quarterly, 15, 3, pp307-320.

McIntyre, L.L., Blacher, J. \& Baker, B.L. (2006). The transition to school: Adaptation in young children with and without intellectual disability. Journal of Intellectual Disability Research, 50, 5, pp349-361.

National Autism Center. (2015). Findings and conclusions, national standards project, phase 2. Retrieved from http://www.nationalautismcenter.org/national-standards-project/

Neitzel, J. (2008). Overview of peer-mediated instruction and intervention for children and youth with autism spectrum disorders. Chapel Hill, NC: National Professional Development Center on Autism Spectrum Disorders, Frank Porter Graham Child Development Institute, The University of North Carolina.

Odom, S. L. and Diamond, K. E. (1998). Inclusion of young children with special needs in early childhood education: The research base. Early Childhood Research Quarterly, 13, 1, pp3-25. 
Odom, S. L., McConnell, S. R. and Chandler, L. K. (1993). Acceptability a feasibility of classroom-based social interaction interventions for young children with disabilities. Exceptional Children, 60, 3, pp226-236.

Rubin, K.H., Coplan, R. Chen, X., Bowker, J.C., McDonald, K. \& Heverly-Fitt, S. (2015). Peer relationships. In M. H. Bornstein \& M.E. Lamb (eds), Developmental Science: An Advanced Textbook. (7th edition). pp587-644. New York: Psychology Press.

Schaefer, B., Shur, K. and Macri-Summers, M. (2004). Preschool children's learning behaviors, concept attainment, social skills and problem behaviors: Validity evidence for preschool learning behavior scale scores. Journal of Psychoeducational Assessment, 22, pp15-32.

Schaefer, C. M., Cannella-Malone, H. I. and Carter E. W. (2016). The place of peers in peermediated interventions for students with intellectual disability. Remedial and Special Education, 37, 6, pp345-356.

Sperry, L., Neitzel, J. and Engelhardt-Wells, K. (2010). Peer-mediated instruction and intervention strategies for students with autism spectrum disorders. Preventing School Failure: Alternative Education for Children and Youth, 54, 4, pp256-264.

Stanton-Chapman, T. L. and Snell, M. E. (2011). Promoting turn-taking skills in preschool children with disabilities: The effects of a peer-based social communication intervention. Early Childhood Research Quarterly, 26, 3, pp303-319.

Stanton-Chapman, T. L., Denning, C. and Jamison, K. (2012). Communication skill building in young children with and without disabilities in a preschool classroom. The Journal of Special Education, 46, 2, pp78-93.

Strain, P. and Hoyson, M. (2000). The need for longitudinal, intensive social skill intervention:

LEAP follow-up outcomes for children with autism. Topics in Early Childhood Special Education, 20, 2, pp116-122.

Suresh, S. and Sandhu, D. (2012). Social skills and well-being: The mediating role of positive relations with others. Indian Journal of Positive Psychology, 3, 1, pp71-74.

Taylor, A. S., Peterson, C. A., McMurray-Schwartz, P., \& Guillou, T. S. (2002). Social skills interventions: Not just for children with special needs. Young Exceptional Children, 5, 4, pp19-26.

Terpstra, J. E. (2004). A comparison of single and combined social interaction interventions to increase the social interaction of preschool children in inclusive settings (Doctoral dissertation). Retrieved from ProQuest Dissertations \& Theses A\&I. (Order No. 3143393).

Webster-Stratton, C. \& Reid, J. (2004). Strengthening social and emotional competence in young children- The foundation for early school readiness and success. Infants and Young Children, 17, 2, pp 96-113. 
Wentzel, K.R., McNamara-Barry, C., \& Caldwell, K.A. (2004). Friendships in middle school: Influences on motivation and school adjustment. Journal of Educational Psychology, 96, 2, pp195-203.

Wentzel, K. R. (2009). Peers and academic functioning at school. In K. H. Rubin, W. M. Bukowski, \& B. Laursen (eds), Handbook of peer interactions, relationships, and groups (pp531-547). New York, NY: Guilford Press.

Wong, C., Odom, S. L., Hume, K. Cox, A. W., Fettig, A., Kucharczyk, S., ... Schultz, T. R. (2014). Evidence-based practices for children, youth, and young adults with Autism Spectrum Disorder. Chapel Hill: The University of North Carolina, Frank Porter Graham Child Development Institute, Autism Evidence-Based Practice Review Group. Retrieved from http://fpg.unc.edu/sites/fpg.unc.edu/files/resources/reports-and-policy-briefs/ 2014-EBP-Report.pdf

Wylie, R. E., Devoney, C., Guralnick, M. J. and Rubin, H. (1974). Integrating handicapped and nonhandicapped preschool children: Effects on social play. Childhood Education, 50, 6, pp360-364.

Ziv, Y. (2012). Social information processing patterns, social skills, and school readiness in preschool children. Journal of Experimental Child Psychology, 114, pp 306-320. 


\section{Biographical information for authors:}

Tricia van Rhijn is a Registered Early Childhood Educator and an Associate Professor in the Department of Family Relations and Applied Nutrition at the University of Guelph. Her research interests include early childhood education and care, family relations, work-life integration, and the experiences of non-traditional students in formal postsecondary education, in particular mature students and student parents.

Caitlyn Osborne is a Registered Early Childhood Educator and a PhD student at Ryerson University in the Policy Studies program. Her research interests include early childhood education and care, inclusive early childhood education, and more specifically recruitment and retention of the early childhood education workforce.

Sarah Ranby is currently completing her Master's of Science in Family Relations and Human Development at the University of Guelph. She is a Bachelor of Arts graduate in the Psychology Co-op program at the University of Guelph. Her current research interests include mental health, social-emotional development of children and program evaluation, in particular, analyzing the effectiveness of community-based interventions and supports that promote positive mental health in young children.

Kimberly Maich is a certified teacher, a special education specialist, and a Board-Certified Behaviour Analyst-Doctoral. She is an Associate Professor in the Faculty of Education at Memorial University of Newfoundland. Her research focus on special/inclusive services in school-based practice, including autism spectrum disorders, emotional/behavioural disorders, and assistive technology.

Carmen Hall is a Board-Certified Behaviour Analyst-Doctoral and a Coordinator/Professor in the Autism \& Behavioural Science Graduate Certificate Program Fanshawe College. She has worked with children with ASD in a number of different environments, including the school setting and intensive behavioural intervention. She has also been involved in consulting roles at schools and in clinical environments, focusing on social skills research, including peer-mediated social skills in child care, school, and camp settings.

Lauren Rzepecki is currently completing her Master's of Arts in Child Study and Education at the Ontario Institute for Studies in Education at the University of Toronto. She is a recent Bachelor of Applied Science graduate in the Child, Youth and Family program at the University of Guelph. Her current research interests broadly include child development, play-based learning, and early childhood education and care.

Amanda Hemmerich is a Registered Early Childhood Educator and a recent graduate of the Child, Youth and Family program at the University of Guelph. Her employment and volunteer commitments relate to her interests involving early childhood education, special/inclusive services in school-based practices, and the impact of emotional/behavioural exceptionalities on childhood development. 